\title{
Predation of the Japanese keelback (Hebius vibakari Boie, 1826) by the Slender racer (Orientocoluber spinalis Peters, 1866)
}

\author{
II-Kook Park', Jaejin Park², Jiho Park', Seong-Hun Min', Alejandro Grajal-Puche ${ }^{4}$ and Daesik Park ${ }^{1 *}$ (D)
}

\begin{abstract}
Background: The Slender racer (Orientocoluber spinalis Peters, 1866) has recently been reclassified to the new genus Orientocoluber from Hierophis. Ecological knowledge of this species is limited due to its highly mobile behavior. On 17 July 2020, we captured a female O. spinalis on Oeyeon Island, Boryeong-si, Republic of Korea, and collected its feces for a diet analysis. We observed snake scales from the collected feces and subsequently determined the prey species through morphological and molecular methods.

Results: We initially hypothesized that the extracted fecal sample scales belonged to $H$. vibakari, due to their thin keel and rhombus shape. We also amplified H. vibakari DNA from the extracted fecal sample using Illumina sequencing methods. Our morphological and molecular results suggest that $O$. spinalis predates $H$. vibakari on Oeyeon Island.

Conclusion: This is the first report of $O$. spinalis predating another snake species, ophiophagy, and implies that $H$. vibakari may be a crucial prey item for $\mathrm{O}$. spinalis on Oeyeon Island.
\end{abstract}

Keywords: Hebius vibakari, Island, Ophiophagy, Orientocoluber spinalis, Predation

\section{Background}

The Slender racer (Orientocoluber spinalis Peters, 1866), which is a cylindrical and slender bodied non-venomous oviparous snake with a medium to moderately long tail, has recently been classified to a new genus Orientocoluber from Hierophis (Kharin 2011; Park et al. 2020). Although $O$. spinalis has a wide geographic range which spans across northeast Asia including China, Kazakstan, North and South Korea, Russia, and Mongolia (Kharin and Akulenko 2008), there are few studies examining its general ecology due to its highly mobile behavior (Kim and Han 2009). In Korea, they are mainly found on hillsides or in high, dry valleys, where they can easily escape into grass or low shrubs (Shannon 1956). Orientocoluber spinalis is likely a diurnal species and may prey upon

\footnotetext{
* Correspondence: parkda@kangwon.ac.kr

'Division of Science Education, Kangwon National University,

ChuncheonKangwon, 24341, Republic of Korea

Full list of author information is available at the end of the article
}

lizards, frogs, and rodents (Won 1971; Kim and Han 2009), although there have been no official publications on the diet of this species. Understanding the diet of $O$. spinalis can provide valuable ecological knowledge and allow for the proactive conservation of local populations (Sih et al. 1998; Werhahn et al. 2019). In this study, we are the first to identify scales and DNA of the Japanese keelback (Hebius vibakari Boie, 1826) in the feces of $O$. spinalis.

\section{Materials and methods}

The initial capture and observations were made on Oeyeon Island $\left(36.228851^{\circ} \mathrm{N}, 126.084288^{\circ} \mathrm{E} ; 143 \mathrm{~m}\right.$ above sea level), Boryeong-si, Chungnam, Republic of Korea. Oeyeon Island is approximately $2.18 \mathrm{~km}^{2}$ in size and is located $30 \mathrm{~km}$ from the west coast of the Korean Peninsula. To date, five reptile species have been reported on the island: four snakes (O. spinalis, Elaphe dione, H. vibakari, and Gloydius brevicaudus) and one

(c) The Author(s). 2021 Open Access This article is licensed under a Creative Commons Attribution 4.0 International License, which permits use, sharing, adaptation, distribution and reproduction in any medium or format, as long as you give appropriate credit to the original author(s) and the source, provide a link to the Creative Commons licence, and indicate if changes were made. The images or other third party material in this article are included in the article's Creative Commons licence, unless indicated otherwise in a credit line to the material. If material is not included in the article's Creative Commons licence and your intended use is not permitted by statutory regulation or exceeds the permitted use, you will need to obtain permission directly from the copyright holder. To view a copy of this licence, visit http://creativecommons.org/licenses/by/4.0/. 
lizard (Scincella vandenburghi; NIE 2016). On 17 July 2020, at 9:40 am, one $O$. spinalis was observed basking on stone stairs near the entrance of a hiking trail and was subsequently captured utilizing a snake hook. Morphometric measurements including snout-vent length (SVL) and tail length (TAL) were recorded using a tape measure. The individual's body weight (BW) and sex were recorded using a spring balance and probe, respectively. Fecal samples were collected by gently pressing the snake's abdomen and directing the cloaca into a $2 \mathrm{ml}$ conical tube, containing 99.5\% ethanol (Beja-Pereira et al. 2009). The snake was immediately released at the initial capture site after all morphometric data and the fecal sample were collected. The fecal sample was initially analyzed under a stereoscopic microscope (Swift S7 7x-45x; Swift Optical Instruments, USA) and an optical microscope (DW-BMS1000; Dongwon, Republic of Korea). From our microscopy work, we discovered snake scales within the fecal sample.

To determine the prey snake species collected from the fecal sample, we compared its general morphological features (shape, presence of keels, etc.) with those of the scales of other snake species found on Oeyeon Island (Koo et al. 2017). We also molecularly determined the species of snake the fecal sample scales may have belonged to. DNA was extracted from the fecal sample using the DNeasy Mericon Food kit (Qiagen, Germany). The extracted DNA was amplified with the vertebrate universal primer (12S-V5) for mitochondrial $12 \mathrm{~S}$ ribosomal RNA (12S rRNA) gene using the PCR protocols reported (Riaz et al. 2011). The amplified PCR products were sent to Macrogen (Republic of Korea) for nextgeneration (Illumina) sequencing. The fecal sample DNA library was sequenced using the Illumina Miseq platform (Illumina, USA) with a $2 \times 300 \mathrm{bp}$ paired end run using Herculase II Fusion DNA Polymerase Nextera XT Index Kit V2 (Illumina, USA). The sequenced DNA data was trimmed using Cutadapt (Martin 2011) to remove any Illumina adaptor and primer sequences. Sequence reads were quality-filtered, denoised, merged, and any chimeric reads were removed using DADA2 bioinformatics package (Callahan et al. 2016) in RStudio v3.5.3 (Team RStudio 2015). The resulting amplicon sequence variant (ASV) FASTA file from fecal DNA of $O$. spinalis was queried against the NCBI database using the Basic Local Alignment Search Tool (BLAST).

\section{Results and discussion}

The captured $O$. spinalis was measured, weighed, and sexed (SVL, $54.6 \mathrm{~cm}$; TAL, $18.1 \mathrm{~cm}$; BW, $35.6 \mathrm{~g}$, female). Some of the dorsal scales extracted from the fecal sample had a thin keel running down the center, were rhomboidal in shape, and were morphologically similar to both $H$. vibakari and G. brevicaudus, which are known inhabitants of Oeyeon Island (Koo et al. 2017). However, the thick keels observed on the extracted scales, more closely resembled scales from $H$. vibakari (Fig. 1). Orientocoluber spinalis lacks any keel morphology on its dorsal scales (Kim and Han 2009; Kharin 2011). Consequently, we could exclude O. spinalis as the potential prey species. The width and length of the 10 ventral scales, extracted from the fecal sample, were $6.3 \pm 0.3$ $\mathrm{mm}$ and $1.2 \pm 0.1 \mathrm{~mm}$, respectively, and the rounded edges of the dorsal scales both corroborated our hypothesis that the prey snake may have been a juvenile Hebius spp. (Fig. 1). Juvenile Hebius spp. have rounded dorsal scales which gradually become more notched as the animal matures (Tsai et al. 2018). In addition to our microscopic observations, we also applied Illumina sequencing methods to identify potential prey items from the collected fecal sample.

Our molecular analysis amplified two reptile species, $H$. vibakari and $O$. spinalis. Given that $O$. spinalis was the predatory species, we concluded that the extracted fecal sample scales were likely from $H$. vibakari, although this does not completely rule out the possibility that $O$. spinalis may be cannibalistic. The $12 \mathrm{~S}$ rRNA sequence from fecal DNA assay yielded 249,148 total sequence reads, and 91,170 preprocessed reads. The highest proportion (40.0\%) of these reads corresponded to O. spinalis, followed by H. vibakari (17.1\%).

The results of our morphological and molecular analysis support our hypothesis that the prey snake scales, extracted from the fecal sample, are likely from $H$. vibakari. In this study, we did not collect the snakes gut contents through regurgitation because this method is likely more invasive and stressful on the animal and would have likely yielded similar results to our fecal collection protocol. Currently, the prey breath of O. spinalis is only anecdotally known and includes lizards, frogs, and rodents (Won 1971; Kim and Han 2009). This is the first report of O. spinalis consuming another snake species, ophiophagy, and potentially cannibalizing its own species. The phylogenetically related but smaller Eirenis spp. (mean SVL 30 cm, Nagy et al. 2004; Das et al. 2019) forages on lizards and arthropods but has not been reported predating other snakes (Çiçek and Mermer 2007; Mahlow et al. 2013). On the other hand, the larger Hierophis viridiflavus and $H$. gemonensis (mean SVL $\sim 130 \mathrm{~cm}$ ) may consume other snakes including Zamenis longissimus and Vipera aspis (Lisičić et al. 2011; Lelièvre et al. 2012). Additional studies should be conducted to identify the prey breadth of $O$. spinalis and to verify if $H$. vibakari is commonly consumed by $O$. spinalis.

\section{Conclusion}

We report the predation of $H$. vibakari by O. spinalis on Oeyeon Island, Korea. The predation of $H$. vibakari by 

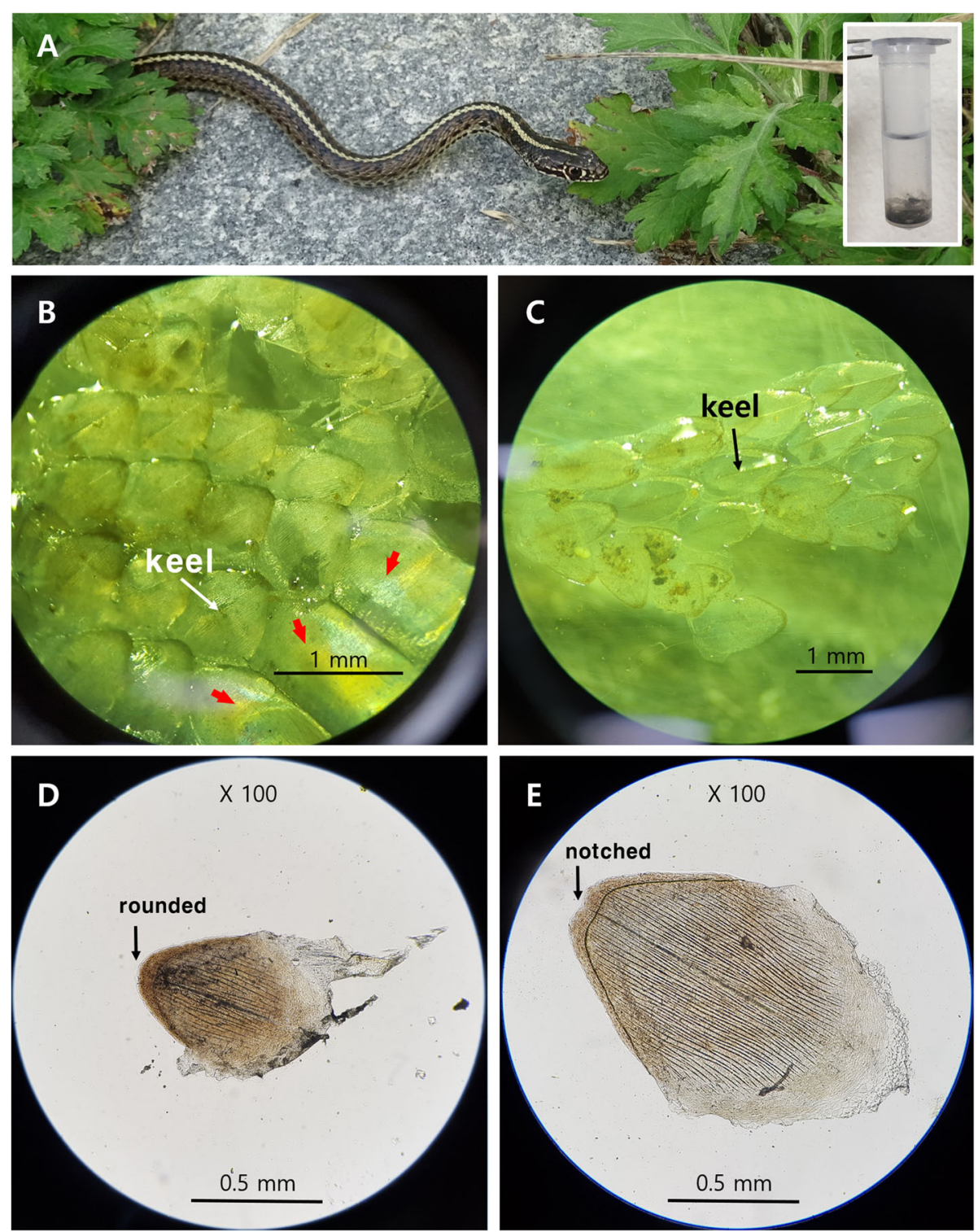

Fig. 1 (A) The captured and sampled female Orientocoluber spinalis, from Oeyeon Island, Republic of Korea, with dorsal and ventral scales placed within a conical vial. (B) Microscopic images of the dorsal and ventral scales (designated by red arrows) collected from the fecal sample. (C) Microscopic images of the extracted dorsal scales to exemplify the keel morphology. (D) Magnified photographs of the extracted dorsal scales and of a sub-adult H. vibakari (E) captured on the same island, for comparison

G. ussuriensis and Sibynophis chinensis has been previously reported in Jeju Island, Republic of Korea (Chang et al. 2010; Kim and Oh 2014). Considering the relatively simple food web on island ecosystem (Boback 2003; Roslin et al. 2014), H. vibakari may be a crucial prey item for $O$. spinalis on Oeyeon Island. Thus, the reduction of $H$. vibakari on Oeyeon Island may have negative population-level effects on $\mathrm{O}$. spinalis. This diet information has the potential to better refine future conservation efforts of $O$. spinalis on Oeyeon Island and beyond.

\section{Abbreviations}

SVL: Snout-vent length; PCR: Polymerase chain reaction; NCBI: National Center for Biotechnology Information; BLAST: Basic local alignment search tool

Acknowledgements

Not applicable.

\section{Authors' contributions}

$I P, J J P, J H P$, and SM carried out the field study and performed the analysis. $I P, J J P, A G$, and DP wrote and reviewed the manuscript. All authors read and approved the final manuscript. 


\section{Funding}

This research was supported by the Basic Science Research Program through the National Research Foundation of Korea (NRF) funded by the Ministry of Education (No. 2020R111A3051885).

\section{Availability of data and materials}

All data involved in this study is available from the corresponding author upon request.

\section{Declarations}

\section{Ethics approval and consent to participate}

This study was approved by the Institutional Animal Care and Use Committee in Kangwon National University (KW-200707-3). The study, capture, handling, and release of the Slender racer on Oeyeon Island was conducted with permission from the Chungnam Provincial Government (2020-1)

\section{Consent for publication}

Not applicable.

\section{Competing interests}

The authors declare they have no competing interests.

\section{Author details}

${ }^{1}$ Division of Science Education, Kangwon National University, ChuncheonKangwon, 24341, Republic of Korea. ${ }^{2}$ Department of Regional Innovation, Kangwon National University, ChuncheonKangwon, 24341, Republic of Korea. ${ }^{3}$ Department of Biology, Kangwon National University, ChuncheonKangwon, 24341, Republic of Korea. ${ }^{4}$ Department of Biological Sciences, Northern Arizona University, Flagstaff, AZ 86001, USA.

Received: 21 July 2021 Accepted: 5 October 2021

Published online: 18 October 2021

\section{References}

Beja-Pereira A, Oliveira R, Alves PC, Schwartz MK, Luikart G. Advancing ecological understandings through technological transformations in noninvasive genetics. Mol Ecol Resour. 2009;9(5):1279-301. https://doi.org/10.1111/j.17550998.2009.02699.x.

Boback SM. Body size evolution in snakes: evidence from island populations. Copeia. 2003;2003(1):81-94. https://doi.org/10.1643/0045-8511(2003)003[0081: BSEISE]2.0.CO;2.

Callahan BJ, McMurdie PJ, Rosen MJ, Han AW, Johnson AJA, Holmes SP. DADA2: high-resolution sample inference from Illumina amplicon data. Nat Methods. 2016;13(7):581-3. https://doi.org/10.1038/nmeth.3869.

Chang MH, Kim BS, Park SG, Kim TW, Oh HS. First records of the ophiophagy in collared many-toothed snake Sibynophis chinensis in Korea. Korean J Herpetol. 2010;2(1):59-61.

Çiçek K, Mermer A. A preliminary study of the food of the dwarf snake, Eirenis modestus (Martin, 1838) (Serpentes: Colubridae), in Izmir and Manisa Provinces. Turk J Zool. 2007;31(4):399-402.

Das S, Campbell PD, Roy S, Mukherjee S, Pramanick K, Biswas A, et al. Cranial osteology and molecular phylogeny of Argyrogena fasciolata (Shaw, 1802) (Colubridae: Serpentes). Verteb Zool. 2019;69(3):311-25.

Kharin VE. Rare and little-known snakes of the north-eastern Eurasia. 3. On the taxonomic status of the Slender racer Hierophis spinalis (Serpentes: Colubridae). Curr Stud Herpetol. 2011;11(3-4):173-9.

Kharin VE, Akulenko MV. Rare and little-known snakes in North-Eastern Eurasia. 1. On a new record of Slender racer-Hierophis spinalis (Colubridae) in the Russian Far East. Curr Stud Herpetol. 2008;8(2):160-9.

Kim BS, Oh HS. Foods use of the red-tongued viper snake (Gloydius ussuriensis). Korean J Environ Ecol. 2014;28(6):657-63. https://doi.org/10.13047/KJEE.2014.2 8.6.657.

Kim LT, Han GH. Animal of Chosun (amphibian and reptiles): Science and Technology Publisher; 2009.

Koo KS, Park SH, Kim JS, Kwon S, Choi WJ, Park IK, et al. The comparison of size and morphology of scales in nine Korean snake species ( 6 in Colubridae, 3 in Viperidae). Korean J Environ Ecol. 2017;50(2):207-15. https://doi.org/10.11614/ KSL.2017.50.2.207.
Lelièvre $H$, Legagneux $P$, Blouin-Demers $G$, Bonnet $X$, Lourdais $O$. Trophic niche overlap in two syntopic colubrid snakes (Hierophis viridiflavus and Zamenis longissimus) with contrasted lifestyles. Amphibia-Reptilia. 2012;33(1):37-44. https://doi.org/10.1163/156853811X620022

Lisičić $D$, Počanić $P$, Lovrić $V$, Derežanin $L$, Tadić $Z$. A case of cannibalism in Hierophis gemonensis preying on conspecific adult. Hyla: Herpetol Bull. 2011; 2011(2):35-6.

Mahlow K, Tillack F, Schmidtler JF, Müller J. An annotated checklist, description and key to the dwarf snakes of the genus Eirenis Jan, 1863 (Reptilia: Squamata: Colubridae), with special emphasis on the dentition. Vertebr Zool. 2013:63(1):41-85.

Martin M. Cutadapt removes adapter sequences from high-throughput sequencing reads. EMBnet J. 2011;17(1):10-2. https://doi.org/10.14806/ej.1 7.1.200.

Nagy ZT, Lawson R, Joger U, Wink M. Molecular systematics of racers, whipsnakes, and relatives (Reptilia: Colubridae) using mitochondrial and nuclear markers. J Zool Syst Evol Res. 2004;42(3):223-33. https://doi.org/1 0.1111/j.1439-0469.2004.00249.x.

NIE. 4th National Ecosystem Survey. National Institute of Ecology; 2016.

Park J, Park IK, Ra NY, Min SH, Park D. Complete mitochondrial genome of the slender racer (Orientocoluber spinalis Peters, 1866; Squamata, Colubridae). Mitochondrial DNA B: Resour. 2020;5(3):2693-4. https://doi.org/10.1080/23 802359.2020.1787257.

Riaz T, Shehzad W, Viari A, Pompanon F, Taberlet P, Coissac E. ecoPrimers: inference of new DNA barcode markers from whole genome sequence analysis. Nucleic Acids Res. 2011;39(21):e145. https://doi.org/10.1093/nar/ gkr732.

Roslin T, Várkonyi G, Koponen M, Vikberg V, Nieminen M. Species-area relationships across four trophic levels-decreasing island size truncates food chains. Ecography. 2014;37(5):443-53.

Shannon FA. The reptiles and amphibian of Korea. Herpetologica. 1956;12(1):2249.

Sih A, Englund G, Wooster D. Emergent impacts of multiple predators on prey. Trends Ecol Evol. 1998;13(9):350-5. https://doi.org/10.1016/S0169-534 7(98)01437-2.

Team RStudio. RStudio: integrated development for R. Boston: RStudio, Inc.; 2015. URL http://www.rstudio.com 42(14): 84

Tsai TS, Mao JJ, Chan YY, Lee YJ, Fan ZY, Wang SH. Species identification of fragmented or faded shed snake skins by light microscopy. Zool Sci. 2018; 35(4):330-52. https://doi.org/10.2108/zs180016.

Werhahn G, Kusi N, Li X, Chen C, Zhi L, Martín RL, et al. Himalayan wolf foraging ecology and the importance of wild prey. Glob Ecol Conserv. 2019;20:e00780. https://doi.org/10.1016/j.gecco.2019.e00780.

Won HG. Amphibian and reptiles of Chosun. Pyeongyang: Pyeongyang Printing Office; 1971.

\section{Publisher's Note}

Springer Nature remains neutral with regard to jurisdictional claims in published maps and institutional affiliations.

Ready to submit your research? Choose BMC and benefit from:

- fast, convenient online submission

- thorough peer review by experienced researchers in your field

- rapid publication on acceptance

- support for research data, including large and complex data types

- gold Open Access which fosters wider collaboration and increased citations

- maximum visibility for your research: over $100 \mathrm{M}$ website views per year

At BMC, research is always in progress.

Learn more biomedcentral.com/submissions 